\title{
Ancestral Veda Concepts and Quantum Mechanic as a background of Ayurveda and Modern Medicine
}

\author{
ALFREDO LAURIA
}

Ayurveda deals with the relationship between communications and forces to be present either in the human beings or in their environment, including the influence either from their family or social and cultural processes. The exchange between man and nature or environment is a whole and dynamic balance. The outcome of this single or unique dialogue can be more or less harmonious; so that the consequence will determine health status: balanced or imbalanced. This relationship of Communication and Integrated Intelligence plays its role in the microcosm, by the way, in the person itself. In Addition it is being inserted into the world or macrocosm, and it is named awareness. I want to quote some examples of this reality that is, actually, unavoidable. In fact, it can not be excluded from the philosophical and practical principles of medicine.

I chose as an example, in the following case:

In Africa, a number of droughts occurred, which have had a devastating effect on local fauna and flora. A pretty endurance antelope called kudú, was researched. These desert antelopes have always fed on shrubs. In 1982 reports came in a large numbers which the kudus were dying in the northern Transvaal. After studying this rare situation, the Scientists found out that the animals were dying of malnutrition; despite they had had adequate amounts of food into their intestines. After checking the trees' leaves in the environment, the experts found out the protein content of the leaves, which the kudu's were eating, was high enough to keep them healthy and well nourished. They also found that the protein content in their faeces were high, so it showed out that the food was passing directly through the guts, undigested. The digestion of ruminants, such as kudu, takes place in a long series of steps in their gut, where the microbes produce fermentation. Actually, the microbes were not obviously doing their work on these kudus, on the other hand, they were burning the fat from their bodies and they were just getting thinner and exhausted.

The microbes were not fulfilling their function and the reason was that the gut flora had been destroyed by a group of chemicals known as tannins; these tannins had been also found in food. In addition a tannins concentration in trees and leaves were unusually high. Furthermore the tannins are part of the defense of many plants to protect themselves so not to serve be used as a food excessively. Plants release deterrents so that the leaves and bark become bitterer in order to deter herbivores. If we look at how the kudu eats, they normally grazes a bush or a tree only for a while, as a rule less than two minutes. Once the kudu's starts eating, plants release chemical defenses; so they do it at an astonishing rush. The Kudu is a massive animal with four feet tall and about 150 kilos. There is a moderate room. So in the first set of tests, scientists took samples and checked them, standing on tiptoe and tearing a piece at a time. Then they imitate the action of moving as a kudu group and hitting plants with belts and sticks, they were mimicking the effect caused by a group of kudu to come to browse, then more samples were taken at regular intervals. The outcomes of these two sets of tests were spectacular. All trees that had been abused in this way, as if they had been eaten by kudu, produced an extra amount of tannins. They produced tannin concentrations above 300 percent and produced them in seconds. Two minutes to attack an acacia tree, a bush or ivy, the three of them became "paranoid" and inedible. All of them remained for at least twenty four hours. Normally, this should 
not have posed a problem for kudu, but another situation had happened in South Africa in the last decade. Recently, farmers who enjoy having wildlife around them, have been installing wild animal-proof fences two feet high. It is a fence high enough to prevent that the agile kudus are lost in areas where they can be shot. When drought conditions became unbearable, the animals were forced to eat from trees that had not had time to recover from their last attack. Tannin concentrations remained too deadly for the animals and they starved and died. This solved the mystery of the dead kudu, but raised another surprise and this is the best part about the whole thing! The team that conducted the study was careful enough to take samples of similar trees that had not been disturbed, in order to serve as control of those which had been beaten with belts and which had been abused. Surprisingly, if the trees were not damaged they were not anywhere close to that of those which had been damaged, demonstrating an increase in their empathetic tannin concentrations. It was almost as if the trees had been under attack as if they had warned others of the same species of the imminent danger!

The South African group failed to get their work published in any scientific publication but magazines. Four years passed before the South African group was supported by two new studies from the United States. In these reports, poplars, maples, alders and willows behaved similarly. They noticed another report of a plague of caterpillars. Laboratory studies conducted in Washington state have been very clear that this communication takes place between trees via chemical airborne, in the same way as our hormones are used to make signals in persons.

The communication and coordination response given between species of the same family demonstrates how a real system is formed where each species is a unit in itself and yet is part of a whole level of complexity. This integrated and coordinated system is explained by the intrinsic factor, also called Creative Intelligence. This Creative Intelligence permeates everything; it is an integrated and inclusive knowledge present in everything that is alive, whether visible or invisible, folding or unfolding, manifested or unmanifested. Moreover the interaction between species (matter) and the environment becomes so intimate, therefore dissipates the "apparent" and mistaken sense of separation and fragmentation, to become an indivisible unity consciousness, intelligent and plenty of fullness or ananda! (happiness).

As David Bohm said:

"What from our point of view is a big bang, from the standpoint of empty space, is a wave. That is, the entire universe is a tiny wave on a background of emptiness, which is also fullness (ananda)!"

Life is in order and this order is called in Vedanta and Ayurveda, Ishvara. The concept of Ishvara responds to the following equation: Brahma + Maya $=$ Ishvara.

It means the invisible creative principle; which is imperceptible to the sense organs, becomes "visible" in the objective world. That principle should be perceptible; and that is "Maya", which is the "illusory" force in the creation. Maya is an order in itself, which is permeated by intelligent creative principle (Brahman). Maya is adding attributes or qualities to That (Brahman) which still is unmanifested. This special and subtle movement occurs in awareness, by the way it causes that the imperceptible turns into perceptible. This instance means a "quantum leap", which is produced by the Creative Intelligence or Brahman and takes place in a Ishvara's field. Ishvara is the unique and perfect combination of creation, of all objects in the world; either the known or the unknown one. It organizes as well as integrates all orders in the Universe, including man. The creative principle is called Brahman in the Veda, and is identical to 
Atman, this is the essence of Being. Atman is the nature of man, is the creative intelligence, the ultimate and absolute reality. So the result (phala) to know my true nature, actually that is the nature of Atman, brings moksha, liberation.

I want to present other examples that involve us, as a human being. In 1973, a special unit of study based in Massachusetts, reported to the Ministry of Health, Education and Welfare their discoveries on the chances of survival after suffering from coronary atherosclerosis. According to their outcomes, the main determining factor for survival was not one of the risk factors that are usually classified as Global Cardiovascular Risk (GCVR) such as smoking, high blood pressure, diabetes, elevated blood cholesterol, etc.; but it was the "job satisfaction". The second general predictor factor was the special unit called "general happiness".

For the holistic medicine, such as Ayurveda, which arises from the huge source of knowledge called Veda, happiness or unhappiness; both are described as one of the goals of growth, balance and health. One school of Ayurveda's thought, was Charaka's school, where we found the first known writings. They are the large collection of Charaka Samhita.

In Charaka it is being expressed as follows:

"The field of Ayurveda is life, happiness and unhappiness, health and unhealth" Indeed, the only search and the best and highest accomplishment that one can hope; is moksha, it is the real freedom from self-confusion, selfignorance, about who we really "are". It is an objective included in Ayurveda, the goal of healing or cure. In my humble opinion, it is the only achievement to be conducted in the field of medicine. It is an accomplishment already achieved due to it is "Myself". Happiness can not be searched out of yourself as an object, because I am that, the happiness, but "limitless", that is my real nature. Actually, there is no object called "happiness", due to I am already "That", it can neither be an object of knowledge nor separate from me. This is important; I should recognize the relationship of identity between Atman and Brahman. When I realize who I am, then I recognize that all created is an oneness, it is the whole.

The second research asks:

\section{Are the Weak Social Relationships a risk factor for Health?}

148 studies were analyzed and included 308,849 patients with average age of 63.9 (49\% women and $51 \%$ men). The parameters were studied and primarily classified functionally and structurally (or a combination of both)

\section{Functional Issues:}

\begin{tabular}{|l|c|c|c|}
\hline $\begin{array}{l}\text { Support } \\
\text { Received }\end{array}$ & Emotional & Information & Material \\
\hline $\begin{array}{l}\text { Perception of } \\
\text { Social Support }\end{array}$ & Emotional & Information & Material \\
\hline Loneliness & $\begin{array}{c}\text { Feeelings of } \\
\text { Isolation }\end{array}$ & Apahty & $\begin{array}{c}\text { Not } \\
\text { Belonging }\end{array}$ \\
\hline
\end{tabular}

\section{Structural Issues:}

1. Partner Status

2. Social networking (e.g. Number of contacts in the real world)

3. Integration (e.g. Level of participation in various relationships and / or activities, sense of community and identification with a social role)

4. Coexistence (e.g. Living alone against with another person)

5. Social Isolation (e.g. General lack of social relationships and communication, participation and / or absence of confidents)

6. Measures complex integration with various components of the above 


\section{CONCLUSIONS}

1. Individuals with adequate social relationships showed a survival probability of $50 \%$ higher than those whose social relations were poor or inadequate, which remained constant after adjusting for age, sex and diagnosis, and so on. The differences were significant $(\mathrm{P}<0.001)$ for all aspects of social relationships considered, and the association was stronger integration of complex measures $(\mathrm{OR}=1.91,95 \% \mathrm{CI} 1.63$ to 2.23$)$ and lower with binary indicators $(\mathrm{OR}=1.19$, $95 \%$ CI 0.99 to 1.44 ).

2. An adequate social relationships are associated with longer survival being its effect rate comparable to smoking cessation.

3. An adequate social relationship surpasses many risk factors for mortality, such as obesity, sedentary lifestyle, and so on. In 2003 the International Obesity Task Force presented a report, which among other things said that one third of all global deaths were due to complications associated with obesity, sedentary lifestyle and smoking.

Ayurveda makes more emphasis on the eternal bond, on the other hand "subtle", which is established between the different systems and structure / function, that the expression of a particular organ. The matter which makes up a body is not separate or isolated entities; they are part of a whole, which cooperate as well as influence, on a permanent way, to maintain the integrity of life. Since modern physics proves with it discoveries, that a man is a whole so that he or she plays a role within a larger unity, which contains it. Such thing is named "macrocosm" that includes the environment and the universe.

We can not consider the disease as an isolated and individual expression of an organ, that organ is a unit in itself, which is organized to perform certain and specific functions. But it is part of a larger unit which, in turn, is organized to reach functions of another level of complexity. After all, each part forms a system, while it is a subsystem of a higher level of complexity, which is organized and reorganized to form the whole man which means "alive" since the unfolding creation. This is the design that is the creative force, known as Brahman, which is considered the ultimate reality. It is the source of all creation and it is the way back, bound to all those things that have been created and manifested.

The knowledge of Brahman is a peculiar principle, it can not be increased, it can not be improved and fundamentally it can not be denied. This knowledge is knowledge of the "totality". So it is atma-jñanam, brahma-jñanam, knowledge of Brahman, which is Atman.

Any other kind of knowledge, either illustrative or descriptive, etc. is under the influence of any of the three possibilities, as were described above, or it can be improved or increased or denied. The man "known" is studied by natural sciences and man "unknown" is a matter of studying of the science of spirituality (Vedic philosophy, for some religious sciences). The interesting thing to ponder is that the origin of Ayurveda comes from the body of knowledge called Veda, therefore, it includes and is pervaded with the study of man "unknown" or invisible. Actually, in Ayurveda the two streams of study and thought merge, in fact, both constitute and are joined as a single subject matter. Since the man "known" is manifested and expressed, and this is dependent on the subtle aspect, called the invisible man or "unknown." The synthesis of the two objects of study will provide the functional and conscious support to Vedic philosophy, especially Vedanta, which aims its exclusive and direct study, to the Self, which is the intrinsic principle of creation, or in this context, the knowledge of man 
"unknown" or invisible. The book in which we should find the way to unveil the truth of man "unknown", seen as a "real" man; so it is that of our own mind and heart. This is the real field and subject of Vedanta and it is where learning the transcendent meaning of life dwells. The language of the mind and heart is the way that makes up the spiritual life, the understanding of conscious man. The participation of consciousness is considered as the "therapeutic" aspect, even though it is the subtlest therapeutical tool that is prescribed by Ayurveda from the wisdom of Vedanta. The real Ayurvedic physician should know both the physical science, and spiritual science. Since the sense of transcendence is also transmitted to the patient through the prescription of diet, lifestyle changes, and specific medications to promote health or trying to cure certain diseases.

The practice of Ayurveda sums up the life in the structure in relating with the functional aspects, of the physical body and mind. In addition, the dynamic and intelligent integration among all aspects above mentioned is in an intimate and unique union with the most internal and subtle man, who is defined as existence, consciousness and fullness, limitless. This is the definition of Atman or Being. Knowing what one is, an unquestionable truth, across the abyss of the "apparent" separation between body medicine, mind medicine and spiritual medicine. The understanding, of these truths is expressing in the conscious experience of life, is even becoming the medicine (Ayurveda or holistic) in a Science and Art of Living "in Fullness", rather than a (limited) science or the Art of Healing.

ALFREDO LAURIA, Professor of Ayurveda, Maimonides University, Buenos Aires, Argentina. 